\title{
Critical Success Factors for Digitalization Projects
}

\author{
Christian Leyh, Konstanze Köppel \\ Technische Universität Dresden, Chair of Information \\ Systems, esp. IS in Manufacturing and Commerce \\ Helmholtzstr. 10, 01069 Dresden, Germany \\ Email: christian.leyh@tu-dresden.de
}

\begin{abstract}
Our paper provides insights into which critical success factors (CSFs) for digitalization projects are seen as important from the companies' perspective based on an online survey. The results presented in this paper show that CSFs of the dimensions of Corporate organization and Technology are considered to be of particular relevance, as stated by the companies, with Corporate culture, Top management support, and a Unified digital corporate strategy / vision as the three most important CSFs. Therefore, this paper contributes to the CSF research regarding digital transformation and enables the development of practiceoriented recommendations for action and assistance in shaping digital transformation.
\end{abstract}

\section{Motivation}

$\mathrm{T}$ ODAY, more than ever, society is undergoing a rapidly evolving digital transformation: government institutions, households, enterprises, and their interactions are all changing as a result of the increasing prevalence and rapidly growing potential of digital technologies. "It is not too much of a stretch to think we have entered a golden age of digital innovation. Owing to the 50-year march of Moore's Law, we have witnessed the creation of a relatively cheap and increasingly easy-to-use world-wide digital infrastructure of computers, mobile devices, broadband network connections, and advanced application platforms" [1]. For companies, in particular, being able to rely on a deep understanding of information technology (IT), in general, and digital innovation, in particular, has never been more important. The technological possibilities, especially concerning the merging of the physical with the digital world, are leading to fundamental paradigm shifts that affect all industries. Nowadays, enterprises have to participate in global digital networking, improve automation of business processes, and reengineer existing business models to gain momentum in digital innovation. Furthermore, the progressive and steady digitalization of society itself, with associated changes, is also playing a role in the daily lives of enterprises. The consequences of this development and the question of whether these changes should be seen as positive or negative are omnipresent [2]-[6]. Digitalization has long since ceased to be a mere buzzword but has rather become a strategic competitive factor. Moreover, digitalization is often seen as an enabler to increase resilience in companies. Here, the positive effects of digital technologies and business models

\author{
Sarah Neuschl, Milan Pentrack \\ Fraunhofer Center for International Management and \\ Knowledge Economy IMW \\ Neumarkt 9-19, 04109 Leipzig, Germany \\ Email: sarah.neuschl@imw.fraunhofer.de, \\ milan.pentrack@imw.fraunhofer.de
}

are emphasized. The COVID-19 crisis lends new relevance to this thesis, as many companies were only able to maintain certain processes with the help of digital tools (e.g., video conferencing, remote services) [7]-[9].

The imperative came up that companies should use the current pandemic as another starting point or leverage for digital transformation as well as for structural change [10]. In the COVID-19 crisis, it became particularly apparent that the challenge is not merely the implementation and use of digital technologies, since the accompanying appropriate changes at every organizational level, e.g., business process adjustments, business model innovations, and restructuring the company organization itself, are at least of equal importance. Consequently, mastering the challenges posed by digitalization has long since ceased to be merely the task of the IT department but rather the entire company [6].

Activities and projects in digital transformation are usually highly complex and time-intensive, thus leading to great opportunities for companies as well as enormous risks. To avoid being "swallowed up" by the risks, it is imperative for companies to focus on the factors that influence digitalization projects. In this context, various studies (e.g., [11]-[17]) have shown that paying attention to these so-called "critical success factors" (CSFs) can have a positive influence on the success of IT projects and their subsequent use, thus minimizing the project risks.

In both scientific and practice-oriented literature, the CSFs for digitalization projects are primarily discussed against the background of the difference between digitalization projects and "classic IT projects." Taking up this discussion and topic, we set up a long-term research project at the Chair of Information Systems, esp. IS in Manufacturing and Commerce at Technische Universität Dresden that specifically addresses CSFs influencing projects in the context of the digital transformation of enterprises. In a first step, we conducted an extensive systematic literature analysis to identify the CSFs of digitalization projects. Second, we set up an interview study with several selected companies to verify the factors identified in the literature and identify additional factors (see [18]). This resulted in 25 CSFs that form the basis of the third step in the research project and, thus, the basis of this paper. The aim of this third step is to examine the importance/relevance of the identified $25 \mathrm{CSFs}$ for digitalization projects with a quantitative study using an 
online survey. Furthermore, we aim to examine the implementation and characteristics of these factors in the companies' projects as a fourth step (which will not be part of this paper). For the third step, we derived four research questions to guide our analysis. In the following, we will only focus on the central research question for the aim and scope of this paper:

\section{Which critical success factors are considered (particularly) important in digitalization projects?}

Taking up this research question, this paper aims to provide initial answers by presenting and discussing selected results of the online survey. To this end, we structured the paper as follows. This introduction is followed by a brief overview of the theoretical foundations of our study. Afterwards, we present the design of our study and the structure of the questionnaire. Then we describe selected results of the survey. Finally, the paper concludes with a discussion and conclusion with an outlook on further research steps.

\section{THEORETICAL BACKGROUND}

\section{A. Digital Transformation}

Digital transformation is the inner engine of a highly extensive transformation, as the effects of which are technologically detectable but the overall consequences for the economy and society are not traceable. Driven by the fourth industrial revolution, it is not only customer behavior that changed but also the way people, organizations, and industries interact with each other [19]. So far, there is no universal definition of digital transformation in the literature. The terms digital transformation, digitalization, and digital age are frequently used as synonyms. Therefore, we use the term digital transformation (DT) in this study. Despite the different views of DT, we can see that DT is a development driven by digital technologies and constant changes in society as well as companies. DT is described as linking together the changes in strategies, business models, cultures, structures, and processes in companies with the goal of strengthening the company's market position using digital technologies [20]. Furthermore, DT differs from a classic change process based on three specific characteristics: The first characteristic is that DT often starts with the customer. Here, digital customer data, in particular, play a central role. New business models, for example, can emerge from this resource. The second characteristic is that DT represents more than just the optimization of business processes and IT. In general, DT encompasses the complete renewal of the entire business model. The third and final characteristic shows that DT is an open-ended and long-term process. The most profound difference between DT and a classic change process is its open-endedness. It fosters a completely new kind of management challenge, since there have been little to no standards or best practices that companies can draw on for help. Management must start from new premises for the conception and implementation of DT processes [21].
In conclusion, there is no clear definition for DT in science and practice, as various definitions represent DT in a general or highly simplified way. In the context of our study, we define DT as follows:

DT refers to the fundamental transformation of society as well as the economy using digital technologies. DT not only has social, cultural, legal, and political implications but also consequences for all corporate structures and value chains.

For companies to master DT successfully, new business models, strategies, organizational forms, and processes are necessary, as well as a strong customer-centricity.

\section{B. Digitalization Projects}

DT is leading a shift in many companies. The transformation of the company in DT is often traversed in several digitalization projects. However, there is no uniform definition for digitalization projects in the literature. In general, a digitalization project is a project that pursues the goal to digitally transform a specific area of the company. This can involve not only redesigning parts of the working environment but also networking systems or production facilities through machines. In most cases, the benefits of the specific digitalization project for the employee or customer are unclear at the project's start (as they can only be estimated at this point) and are, therefore, overshadowed by fears. This is because many target groups have not yet had any experience with such digitalization projects and are, therefore, unable to assess their future impact. Ignorance and uncertainty are often the biggest hurdles in the implementation of digitalization projects. In DT, companies have a particularly difficult time, because such changes are not only linked to large investments but also to adjustments within the organization in the areas of responsibility and leadership behavior [22]. In any digitalization project, it is important to consider the reservations, wishes, and goals of the various target groups. In general, four phases divide the procedure of a digitalization project: goal setting, strengthening project acceptance, implementation, and control. The first phase derives the objectives and strategies for the DT project. Since this forms the basis of the entire digitalization project, it is essential to involve all target groups. In the second phase, a strategic and tactical concept design of the digitalization project must be developed and implemented in the company. For the successful completion of a digitalization project, it is helpful to define a person responsible for the project who is already familiar with the implementation of DT. Open communication with employees or customers also plays an important role. In the third phase, the actual implementation of the digitalization project takes place through suitable measures in the company. The final phase monitors the success of the digitalization project. In particular, feedback should be obtained from all stakeholders involved in order to derive the potential for improvement [22]. 


\section{Critical Success Factors}

For several decades, practitioners have been dealing with the idea that corporate success is based on specific influencing factors and measures of management. As such, strategies for corporate management have been derived from these influencing factors and measures. As early as 1961, the former McKinsey consultant and later managing director D. R. Daniel developed the theory that management information systems can be used to obtain important information about what he called "success factors" [23], [24]. In practice, success factor research first gained acceptance through the much-cited PIMS study (Profit Impact of Marketing Strategies), which addressed corporate success and its causes in the early 1970s. This was a pioneering study in the field of success factor research. Over the years, other works have also had a significant influence on the domain. For example, Rockart [25] took up the ideas of the initial success factor research and further developed them in his concept of critical success factors using a variety of methods. Rockart [25] conducted intensive interviews with chief executive officers (CEOs) of specific companies to identify success factors. Since 1980, research in the field has changed from specific individual cases to a holistic or industry-specific research of critical success factors [23].

However, the literature defines the term success factors differently. The terms critical success factors, strategic success factors, and key factors are often used as synonyms. In this study, we use the term critical success factors (CSFs). Table 1 shows selected definitions in the literature. The definition by Rockart [25] is the most influential.

TABLE I.

DEFINITIONS OF CSFS

\begin{tabular}{|l|l|}
\hline Reference & Definition \\
\hline$[25]$ & $\begin{array}{l}\text { "Critical success factors thus are, for any business, the } \\
\text { limited number of areas in which results, if they are } \\
\text { satisfactory, will ensure successful competitive } \\
\text { performance for the organization. They are the few key } \\
\text { areas where 'things must go right' for the business to } \\
\text { flourish. If results in these areas are not adequate, the } \\
\text { organization's efforts for the period will be less than } \\
\text { desired." }\end{array}$ \\
\hline$[26]$ & $\begin{array}{l}\text { "Key success factors are those variables which } \\
\text { management can influence through its decisions that } \\
\text { can affect significantly the overall competitive positions } \\
\text { of the various firms in an industry." }\end{array}$ \\
\hline$[27]$ & $\begin{array}{l}\text { "Critical Success Factors (CSFs) are those } \\
\text { characteristics, conditions, or variables that when } \\
\text { properly sustained, maintained, or managed can have a } \\
\text { significant impact on the success of a firm competing in } \\
\text { a particular industry." }\end{array}$ \\
\hline
\end{tabular}

All authors of the definitions presented in Table I point out that CSFs play a decisive role in the success of the company and the project. They can be seen as areas of action for management to continuously and carefully monitor and contribute to the achievement of the company's goals [25]. However, CSFs vary by company and industry. Therefore, it is important for each company to identify the specific CSFs of their industry and respective project areas.

In the first step of our research project, we identified 25 CSFs of DT (see [18]), which form the basis of this paper. Table II lists the 25 CSFs of DT associated with their respective dimensions. A detailed description of each factor as well as a complete ranking of all 25 CSFs related to both the literature review and the interview study from Step 1 can be requested from the authors.

TABLE II.

CSFs of Digitalization Projects (ADAPTED From [18])

\begin{tabular}{|c|c|}
\hline Dimension & CSFs \\
\hline $\begin{array}{l}\text { Corporate } \\
\text { organization }\end{array}$ & $\begin{array}{ll}\text { - } & \text { Corporate culture } \\
\text { - } & \text { Implementation of a digital mindset } \\
\text { - } & \text { Lnified digital corporate strategy / vision } \\
\text { - } & \text { Top management support } \\
\text { - } & \text { Change management } \\
\text { - } & \text { Digital talent in leadership positions } \\
\text { - } & \text { Qualification }\end{array}$ \\
\hline Technology & $\begin{array}{ll}\text { - } & \text { Data collection / Big data analysis } \\
\text { - } & \text { Hardware } \\
\text { - } & \text { Unified database in an overall system } \\
\text { - } & \text { Data security }\end{array}$ \\
\hline Customer & $\begin{array}{l}\text { - Customer centric management model } \\
\text { - } \quad \text { Omni-channel-management }\end{array}$ \\
\hline $\begin{array}{l}\text { Project } \\
\text { management }\end{array}$ & $\begin{array}{l}\text { - Network effects through open systems / } \\
\text { partnerships } \\
\text { - Long-term implementation through short } \\
\text { intensive sprints } \\
\text { - Resources }\end{array}$ \\
\hline $\begin{array}{l}\text { Value } \\
\text { creation }\end{array}$ & $\begin{array}{l}\text { - } \\
\text { - } \\
\text { - } \\
\text { - } \\
\text { - }\end{array}$ \\
\hline $\begin{array}{l}\text { Value } \\
\text { proposition }\end{array}$ & $\begin{array}{ll}\text { - } & \text { Servitization } \\
\text { - } & \text { Fast prototyping } \\
\text { - } & \text { Scalability }\end{array}$ \\
\hline
\end{tabular}

\section{StUdy Design}

\section{A. Structure of the Online Questionnaire}

With our central research question, we aim to gain initial insights into companies' assessments and understandings of CSFs in DT. Therefore, we chose an explorative approach for this study. Accordingly, the study is intended as a starting point for more in-depth investigations of the characteristics of the individual CSFs in the further course of our research project. For this reason, we also make no claim of the representativeness of participants in this study. 
To design our online questionnaire, we looked at existing CSF study designs (e.g., for ERP system implementation projects) and used them for orientation. In total, our questionnaire was divided in three parts:

Part A comprises 11 questions (Part A.1: four questions, Part A.2: seven questions). In Part A.1, the first two questions address the company's industry sector and number of employees. In the last two questions in part A.1, the participant is asked to state his/her position at the company and the location (federal state) of the company. In Part A.2, first, we asked the participant if he/she agrees with the given definition of DT (see Theoretical Background). The next question discusses the company's attitude regarding DT against the background of the current COVID-19 crisis. We then asked whether the pandemic has favored the attitude towards digitalization projects in certain companies. The next three questions address the participants' assessment of the extent to which their companies have already implemented digitalization projects, in general. For this purpose, the first of the three questions was about the company's status in DT. Here, we asked the respondent to indicate if the company has already embedded DT in its business strategy or whether DT is in the early stages at the company. Secondly, we asked the respondent whether the company has already carried out digitalization projects in individual business areas/departments or is planning to do so. In addition to the status and projects in DT, the next question addressed the estimated degree of DT at the company. The last two questions in part A.2 cover the structure of the IT department and the current digital trends the company is focusing on, such as smart factories or IoT.

Part B comprises seven questions. First, the participant must assess all CSFs regarding the perceived influence on the success of digitalization projects. To this end, we query the 25 CSFs within the dimensions of business organization, technology, customer, project management, value creation, and value proposition. Each dimension represents one matrix question (six questions in total). We used the Likert scale as the psychometric response format. The scale value of the Likert scale could be ultimately calculated as the sum or average score of the respective ratings. We chose a 5-point Likert scale to measure the influence of the CSFs of digitalization projects: 1-No influence, 2-Little influence, 3-Medium influence, 4-High influence, 5-Very high influence. After assessing all CSFs, we finally asked the participant to indicate the three CSFs (Top $3 \mathrm{CSFs}$ ) they consider most important in DT.

Parts A and B are relevant for addressing our central research question within this paper. The aim of the final Part C is to evaluate the implementation of the CSFs in the company. Due to the complexity of the factors, it was, unfortunately, not possible to ask about all CSFs. Therefore, we examined only the three CSFs that were determined in the last question in part B as the three most important CSFs of DT. To prevent the questionnaire from becoming too long, we asked a maximum of three questions for each CSF, so that the total number of questions in Part $\mathrm{C}$ did not exceed nine. Hence, the results of Part $\mathrm{C}$ will not be part of this paper.

\section{B. Implementation of the Online Questionnaire and Pre- Test}

For the implementation of the questionnaire, we used the online survey application LimeSurvey. For a better overview, we displayed all the questions of a question group on one page to reduce the number of clicks needed. We designed the questions of Parts $\mathrm{A}$ and $\mathrm{B}$ as mandatory questions. The questions of Part $\mathrm{C}$ are therefore optional to answer. To ensure the same understanding of the response, we gave all terms/concepts a lay-over possibility, allowing participants to see a given definition.

Before the online survey started, we performed a pre-test. The aim of the pre-test was to check the questionnaire instructions and individual items for comprehensibility and errors. Within the scope of the pretest, seven people from the target group (e.g., managing directors, department heads) went through the questionnaire. Their answers were not included in the final data evaluation. Based on their feedback, we made final changes to the online questionnaire.

\section{Data Collection}

For the online survey, we invited companies to participate primarily via emails. We used the AMADEUS company database (https://amadeus.bvdinfo.com/) by Bureau van Dijk as the main source for contact information. The query in the AMADEUS database was limited to "active companies," regardless of industry sector, that provided an e-mail address, were headquartered in Germany, and had at least 20 employees. The latter restriction was made due to complexity reduction and, thus, represents a limitation of our study. From the resulting list, 7360 e-mails were randomly sorted and sent to companies in the period from December 1, 2020, to January 31,2021 . In addition, we shared the link to the online survey in various groups on the XING platform (https://www.xing.com/).

After the survey period closed, the questionnaire was at least partially completed 225 times. Of these 225 questionnaires, 101 were completed in full. Before the data analysis was carried out, the 101 fully completed questionnaires were checked for plausibility. During this plausibility check, attention was paid to whether a pattern was discernible in the evaluation of the CSFs with regard to their influence in the success of the digitalization projects, suggesting that the participant had only clicked through the questionnaire at random. In addition, it was checked whether there was a contradiction in the ranking of the CSFs with its evaluation. We, therefore, needed to exclude four data sets, which meant that 97 data sets could be taken into account for the evaluation of results presented in the following chapter. 


\section{SELECTED RESULTS}

\section{A. General Participants' Characteristics}

First, we asked the 97 participants about the general characteristics of their companies, which included location, industry affiliation, number of employees, and position of the participants (Part A.1).

Companies from all German federal states took part. Most of the participants came from companies in Berlin $(n=13)$ and Lower Saxony $(\mathrm{n}=10)$; the locations of the other participants are balanced across the other federal states. Since we make no claim to representativeness, we have not further divided the results according to the company shares per federal state.

Most of the companies ( $\mathrm{n}=22)$ belong to the manufacturing industry/production of goods. The subsequent dominant sector allocation falls to the provision of economic services $(n=18)$ and education and training $(n=11)$. The remaining companies are distributed roughly equally among the other industry sectors. The aggregation of the individual sectors to the secondary sector (industrial production) or tertiary sector (service enterprises in the broader sense) shows that most companies belong to the service sector $(\mathrm{n}=65)$, and the remaining businesses are industrial enterprises $(n=32)$. According to the indicated number of employees, most of the companies $(\mathrm{n}=70)$ are SMEs (i.e., companies with up to 249 employees). Large companies are in the minority in our sample $(\mathrm{n}=27)$. Approximately half of the participants $(\mathrm{n}=50)$ belong to top management or executive management, whereby $19 \%$ of the participants $(\mathrm{n}=18)$ hold the position of professionals within a specific department. Furthermore, 12 department managers and 13 project managers participated in the survey. Four participants held other positions (e.g., business development, digital officer).

\section{B. Digital Transformation within the Companies}

Following the general question regarding company specifics, we asked seven questions with a specific focus on the characteristics of DT (Part A.2).

First, participants were asked to evaluate (1) a presented definition of DT (see Theoretical Background). Almost twothirds of the participants $(n=63)$ fully agreed with the given definition. One-third of the respondents $(\mathrm{n}=32)$ agreed at least partially. Reasons for partial agreement with the DT definition vary widely. For example, it was noted that each company must overcome individual challenges in the context of DT, and that the definition can, therefore, only be regarded as a rough guide. Furthermore, participants put into perspective that new business models and strategies at existing companies are not necessary for the success of DT.

The companies then assessed to what extent their (2) attitude towards DT has changed due to the COVID-19 crisis. The majority of companies $(n=58)$ indicated that their attitude toward DT has not changed as a result of the current COVID19 crisis, since they had already perceived DT as an important issue. This indicates that many companies had already addressed DT in their strategies or are currently doing so. One-third of the companies $(\mathrm{n}=32)$ perceived DT as more important than before due to the COVID-19 crisis. In turn, five companies indicated that their attitudes toward DT have not changed because of the COVID-19 crisis, in that DT does not play an important role in their companies.

Furthermore, the (3) DT status of the company was of interest: DT was already an integral part of the business strategy in almost half of the companies surveyed $(n=47)$. In $40 \%$ of the companies, there was no overarching corporate strategy for DT, but they had already started or implemented single digitalization projects. Ten companies are currently in the planning phase in digitalization projects, and only one company indicated that it has not yet addressed the issue of DT at all.

The companies were then asked about (4) digitalization projects conducted or planned along key business functions (logistics, production, human resources, purchasing, sales, marketing, accounting/controlling, service, other). In human resources $\quad(n=61)$ marketing $(n=54) \quad$ and accounting/controlling ( $\mathrm{n}=56$ ) functions, most companies have already conducted digitalization projects. One in three companies - cumulatively viewed for all functions-is currently conducting or has already completed digitalization projects.

When asked about the (5) degree of DT at the company, participants were asked to indicate the extent to which they consider their company to be digitalized on a scale from "0" (not digitalized at all) to "10" (fully digitalized). Most companies $(n=76)$ rated their company's level of DT as 5 to 8. Seventeen companies rated themselves with categories of 0 to 4 . The remaining companies assigned themselves scores of 9 or 10.

This was followed by the question on (6) the structure of the IT department (multiple answers were allowed). Most companies $(\mathrm{n}=37$ each) stated that they either have a central and, therefore, "classic" IT department and/or employ an external IT service provider. Approximately $20 \%$ do not have their own IT department, and 15\% employ IT experts directly in individual departments. In nine companies, the IT department is bimodal, which allows the companies to accelerate and drive their digitalization projects in a separate infrastructure. Two companies also indicated that decentralized IT departments exist per functional area.

In the final question of Part A.2, we asked for (7) the DT trend topics the companies have already addressed. The topic that most companies $(n=66)$ have already addressed or are currently focusing on is cloud technologies. While many companies $(\mathrm{n}=34)$ are also focusing on big data, some are also dealing with trends like additive manufacturing processes, IoT, cyber-physical systems, and smart factory. The trends a company chooses to address often also depend on the industry sector. For example, cyber-physical systems or smart factory play a role more often in the manufacturing sector and less frequently in service companies. Some companies also listed additional trends, i.e., artificial intelligence (AI), telematics infrastructure, and hybrid commerce. 


\section{Assessment of CSFs for Digitalization Projects}

The core of our survey consisted of assessing all identified CSFs (see [18]) in terms of their influence on the success of digitalization projects (Part B). First, companies rated their importance using the 5-point Likert scale (1-No influence, 2-Little influence, 3-Medium influence, 4-High influence, to 5-Very high influence). Second, participants chose the three CSFs they considered the most important in terms of the success of digitalization projects (Top 3 CSFs). The respective rankings are shown in Table III. The following results are referring to the left-hand column of Table III. The results of the Top 3 CSFs (right-hand column of Table III) are taken up later in the Discussion section.

The dimension Corporate organization is the largest and comprises eight CSFs. The entire dimension seems to have a high to very high impact (on average, rated with a 4.14), as the participants mostly rated the pertinent CSFs with a four or five:

- About nine out of ten companies rated the CSF of Corporate culture as very important for digitalization projects.

- Most companies rated the CSFs Implementation of a digital mindset and Unified digital corporate strategy/vision as high $(\mathrm{n}=46 ; \mathrm{n}=40)$ to very high $(\mathrm{n}=37$; $\mathrm{n}=38$ ).

- About eight out of ten companies believe that the CSF Leadership has a high $(\mathrm{n}=32)$ or very high $(\mathrm{n}=44)$ impact for digitalization projects.

- For the CSF Top management support, over $50 \%$ of the respondents $(\mathrm{n}=52)$ indicated that this factor has a very high influence in DT project implementation.

- For Change management and Digital talent in leadership positions, the percentage of companies rating the influence as only moderate is higher $(n=20 ; n=16$, ) than for the other CSFs in this dimension. However, even for these two CSFs, companies rated their influence as high $(n=40 ; n=43)$ or very high $(n=31 ; n=24)$.

- The final CSF in this dimension, Qualification, is also rated as having a high $(n=49)$ to very high $(n=32)$ influence with respect to the success of digitalization projects.

TABLE III.

COMPARISON OF THE TWO DIFFERENT RANKINGS OF CSFS FROM QUESTIONNAIRE PART B

\begin{tabular}{|l|c|l|c|}
\hline \multicolumn{2}{|c|}{$\begin{array}{c}\text { Ranking of CSFs based on } \\
\text { average score using the 5-point } \\
\text { Likert scale }\end{array}$} & \multicolumn{2}{c|}{$\begin{array}{c}\text { Ranking of CSFs based on the } \\
\text { indication of the Top 3 CSFs }\end{array}$} \\
\hline Critical success factor & Rank & Critical success factor & Rank \\
\hline Data security & 1 & Corporate culture & 1 \\
\hline Software & 2 & $\begin{array}{l}\text { Unified digital corporate } \\
\text { strategy / vision }\end{array}$ & 2 \\
\hline $\begin{array}{l}\text { Top management } \\
\text { support }\end{array}$ & 3 & $\begin{array}{l}\text { Implementation of a } \\
\text { digital mindset }\end{array}$ & 3 \\
\hline $\begin{array}{l}\text { Unified database in an } \\
\text { overall system }\end{array}$ & 4 & $\begin{array}{l}\text { Top management } \\
\text { support }\end{array}$ & 4 \\
\hline Corporate culture & 5 & Qualification & 5 \\
\hline
\end{tabular}

\begin{tabular}{|c|c|c|c|}
\hline $\begin{array}{l}\text { Implementation of a } \\
\text { digital mindset }\end{array}$ & 6 & Leadership & 6 \\
\hline $\begin{array}{l}\text { Unified digital } \\
\text { corporate strategy / } \\
\text { vision }\end{array}$ & 7 & $\begin{array}{l}\text { Unified database in an } \\
\text { overall system }\end{array}$ & 7 \\
\hline Leadership & 8 & Software & 8 \\
\hline Qualification & 9 & Change management & 9 \\
\hline Resources & 10 & $\begin{array}{l}\text { Digital talent in } \\
\text { leadership positions }\end{array}$ & 9 \\
\hline Change management & 11 & Data security & 11 \\
\hline $\begin{array}{l}\text { Networking of the } \\
\text { entire value network }\end{array}$ & 12 & Resources & 12 \\
\hline $\begin{array}{l}\text { Digital talent in } \\
\text { leadership positions }\end{array}$ & 13 & $\begin{array}{l}\text { Data collection / Big } \\
\text { data analysis }\end{array}$ & 13 \\
\hline $\begin{array}{l}\text { Cross-functional } \\
\text { development teams }\end{array}$ & 14 & $\begin{array}{l}\text { Customer centric } \\
\text { management model }\end{array}$ & 14 \\
\hline Hardware & 15 & $\begin{array}{l}\text { Cross-functional } \\
\text { development teams }\end{array}$ & 14 \\
\hline $\begin{array}{l}\text { Customer centric } \\
\text { management model }\end{array}$ & 16 & Servitization & 14 \\
\hline $\begin{array}{l}\text { Long-term } \\
\text { implementation } \\
\text { through short intensive } \\
\text { sprints }\end{array}$ & 17 & $\begin{array}{l}\text { Networking of the entire } \\
\text { value network }\end{array}$ & 14 \\
\hline Scalability & 18 & Hardware & 18 \\
\hline $\begin{array}{l}\text { Network effects } \\
\text { through open systems / } \\
\text { partnerships }\end{array}$ & 19 & $\begin{array}{l}\text { Long-term } \\
\text { implementation through } \\
\text { short intensive sprints }\end{array}$ & 19 \\
\hline Lean thinking / OpEx & 20 & $\begin{array}{l}\text { Implementation of new } \\
\text { KPIs }\end{array}$ & 20 \\
\hline $\begin{array}{l}\text { Data collection / Big } \\
\text { data analysis }\end{array}$ & 21 & $\begin{array}{l}\text { Omni-channel- } \\
\text { management }\end{array}$ & 20 \\
\hline $\begin{array}{l}\text { Omni-channel- } \\
\text { management }\end{array}$ & 22 & Fast prototyping & 20 \\
\hline Servitization & 23 & Lean thinking / OpEx & 23 \\
\hline Fast prototyping & 24 & $\begin{array}{l}\text { Network effects through } \\
\text { open systems / } \\
\text { partnerships }\end{array}$ & 23 \\
\hline $\begin{array}{l}\text { Implementation of new } \\
\text { KPIs }\end{array}$ & 25 & Scalability & 23 \\
\hline
\end{tabular}

The dimension Technology is the second largest dimension and includes five CSFs. This dimension is also assigned a high to very high influence, as the individual CSFs were predominantly rated as a four or five. On average, companies rated all CSFs in this dimension with 4.11:

- The CSF Data security stands out in having the highest influence on project success in DT: 23 participants perceive a high influence on digitalization projects. Two thirds of the companies $(n=64)$ stated that the influence of this factor is very high.

- For the two CSFs Software and Unified database in an overall system, the influence on the successful implementation of digitalization projects is mainly rated as high $(n=40 ; n=39)$ to very high $(n=50 ; n=44)$.

- The assessment was not so clear-cut for the last two CSFs Data collection / Big data analysis and Hardware. In both cases, participants agreed to a high $(n=34 ; n=41)$ or very high impact $(n=18 ; n=22)$. Compared to the other three CSFs in this dimension, respondents also indicated that these two CSFs each had a rather medium influence $(n=24$ and $\mathrm{n}=21$ ). In addition, about one in ten respondents $(n=11$ and $n=12)$ rated the influence as low in each case. 
The dimension Customer covers the two CSFs Customer centric management model and Omni-channel-management. On average, respondents in this dimension rated the impact of the CSFs on project success in DT only with a 3.54: About half of the respondents each rated the influence of the two CSFs as high to very high. Just under one-fifth of the companies $(n=18 ; n=21)$ rated the influence as medium. Compared to the CSFs of the first two dimensions considered so far, some participants stated that these CSFs have no influence on the success of digitalization projects. This may be due, for example, to the fact that these two CSFs are somewhat more specific for individual industry sectors and many respondents may not be able to assess this for their company.

The three CSFs Network effects through open systems / partnerships, Long-term implementation through short intensive sprints, and Resources belong to the dimension Project management. On average, this dimension is rated with a 3.74. This is slightly above the score for the dimension Customer (3.54) but below the dominant ones (Corporate Organization: 4.14; Technology: 4.11). All three CSFs of this dimension were assigned a high influence on the success of digitalization projects by over $40 \%$ of the companies $(n=40$, $n=45$ and $n=43)$. Almost one-third of respondents $(n=31)$ even rated the influence of Resources as very high. In contrast, for the other two CSFs, a quarter of the companies $(n=24$ and $n=26)$ think that the influence on project success in DT is rather moderate. Furthermore, $15 \%$ of the participants $(\mathrm{n}=12$ and $\mathrm{n}=13$ ) believe that the CSF Network effects through open systems / partnerships has little to no influence on the success of the digitalization projects.

The dimension Value creation consists of four CSFs. On average, there is a rating of 3.59 in this dimension. The influence of the two CSFs Networking of the entire value network and Cross-functional development teams was rated higher than for the other two CSFs. More than $40 \%$ of the companies $(n=39 ; n=43)$ indicated that the two CSFs mentioned had a high influence on project success in DT, and several companies $(n=23 ; n=19)$ even rated this as very high. However, about $22 \%$ of the participants $(n=22$ and $n=21)$ are of the opinion that the two CSFs have only a medium influence on success. With regard to the other two CSFs, Implementation of new KPIs and Lean thinking / OpEx, most companies $(n=35 ; n=34)$ stated that the influence here is neutral.

The final dimension Value proposition includes the three CSFs Servitization, Fast prototyping, and Scalability. On average, participants rated this dimension the lowest of all dimensions with a 3.38. When evaluating the CSF Servitization, 27 of the respondents stated that its influence on the success of the digitalization projects is medium, 21 of the respondents estimated it to be high, and 10 companies very high. For Fast prototyping and Scalability, approximately
$30 \%$ of respondents $(n=29 ; n=30)$ believe that their influence on project success is high. The percentage of respondents who find their influence to be neutral is one-fifth $(n=20)$ and onequarter $(n=23)$, respectively.

\section{V.DISCUSSION}

Regardless of the size of the company, projects within the scope of DT are complex and extensive undertakings, which sometimes lead to strong interventions in the company's processes and daily business. A structured approach to the implementation of digitalization projects can prove highly useful. Therefore, it can be helpful for companies to use CSFs as a guide for the specific implementation of digitalization projects. According to the assessments of the companies surveyed, organizational factors, in particular, play a decisive role in DT. Corporate culture was rated as the most important CSF for digitalization projects (with a view to the Top 3 CSFs, right-hand column in Table III). DT gives rise to new business models, thus companies must adapt and improve business processes for these new circumstances. As these changes often collide with the already existing corporate culture, it is particularly important that companies invest time and resources to create a digital corporate culture. The associated, necessary changes should be openly communicated and, above all, implemented together with the employees (internal co-creation). The newly created corporate culture should have flatter hierarchies and be databased, data-driven, agile, risk-aware, and creative [28]. However, Top management support is also necessary for successful implementation. Without certain commitment and project understanding, most digitalization projects will fail. Since the top management is responsible for the digital transformation strategy, it must also be actively involved in the digital transformation process. Managers should define appropriate goals for DT and harmonize them with the rest of the corporate goals. Regarding DT, it is necessary that the future positioning of a company is anchored in a Unified digital corporate strategy / vision. For a successful implementation of digitalization projects, companies must define corresponding goals, determine expected developments, and derive resulting measures. Due to a strong dependency of corporate strategy and corporate culture, it is important that both are aligned [16], [29]. A particularly helpful exposition for successfully aligning is to implement a digital mindset in the company.

Setting the right course at the organizational and strategic level is one thing - the effective and efficient implementation of concrete projects for DT is another. Since digitalization projects - in their dominant nature as innovation projects (new-to-the-firm or even new-to-the-market) - can have different focuses, not all factors are of the same relevance for every company or every project. Noticing this, we set the identified success factors in relation to the different dimensions of DT. This resulted in a comprehensive model as a starting point for digitalization projects-see Fig. 1. The 
ranks of the Top 10 CSFs shown in this figure refer to the lefthand column in Table III.

When the survey results are integrated into our model (see Fig. 1), the abovementioned discussion becomes clear once again: Most of the Top 10 CSFs are assigned to the dimension Digital corporate organization. The other Top $10 \mathrm{CSFs}$ (except for the CSF Resources) belong to the dimension Digital technology. This can be interpreted that the two dimensions are particularly fundamental and flanking areas, which are, therefore, rated as the most important. The Digital corporate organization permeates the other dimensions of DT and influences all transformation tasks. The technological basis is, in turn, a component of all developments in the other dimensions.

Differences emerge in the results when the data provided by SMEs $(n=70)$ and large companies $(n=27)$ are considered separately:

- Top 3 CSFs of SMEs: Data security, Software, and Top management support.

- Top 3 CSFs of large enterprises: Data security, Corporate culture, and Implementation of a digital mindset.

Looking at the Top 10 CSFs without considering company size (see Table III, left column), the difference between large companies and SMEs is shown, in that both SMEs and large companies consider the dimensions of both Digital corporate organization and Digital technology to be of particular importance. In the case of SMEs, however, technological CSFs rank even higher, whereas large companies give more importance to organizational CSFs. One possible explanation for this difference is that large companies have more resources (human and financial) to create the technological basis for DT - and have already done so to a much greater extent than SMEs.

The distinction between SMEs and large enterprises can shed new light on CSFs, since these have to be interpreted through the background of company specifics in structure and processes (e.g., flatter structures, familiarity, scarcity of resources in SMEs). Since organizations are social systems that consist of complex interactions between individuals and groups, Corporate culture (as a CSF of the dimension Digital corporate organization) is, therefore, incorporated. In this way, shared convictions and attitudes exist in groups, which influence the perception, reactions to changes, and, consequently, the occurrence of resistance/barriers [30]. Corporate culture, thus, has an influence on perceptions, attitudes, and behaviors [31], which, in turn, influence the success of digitalization projects [32].

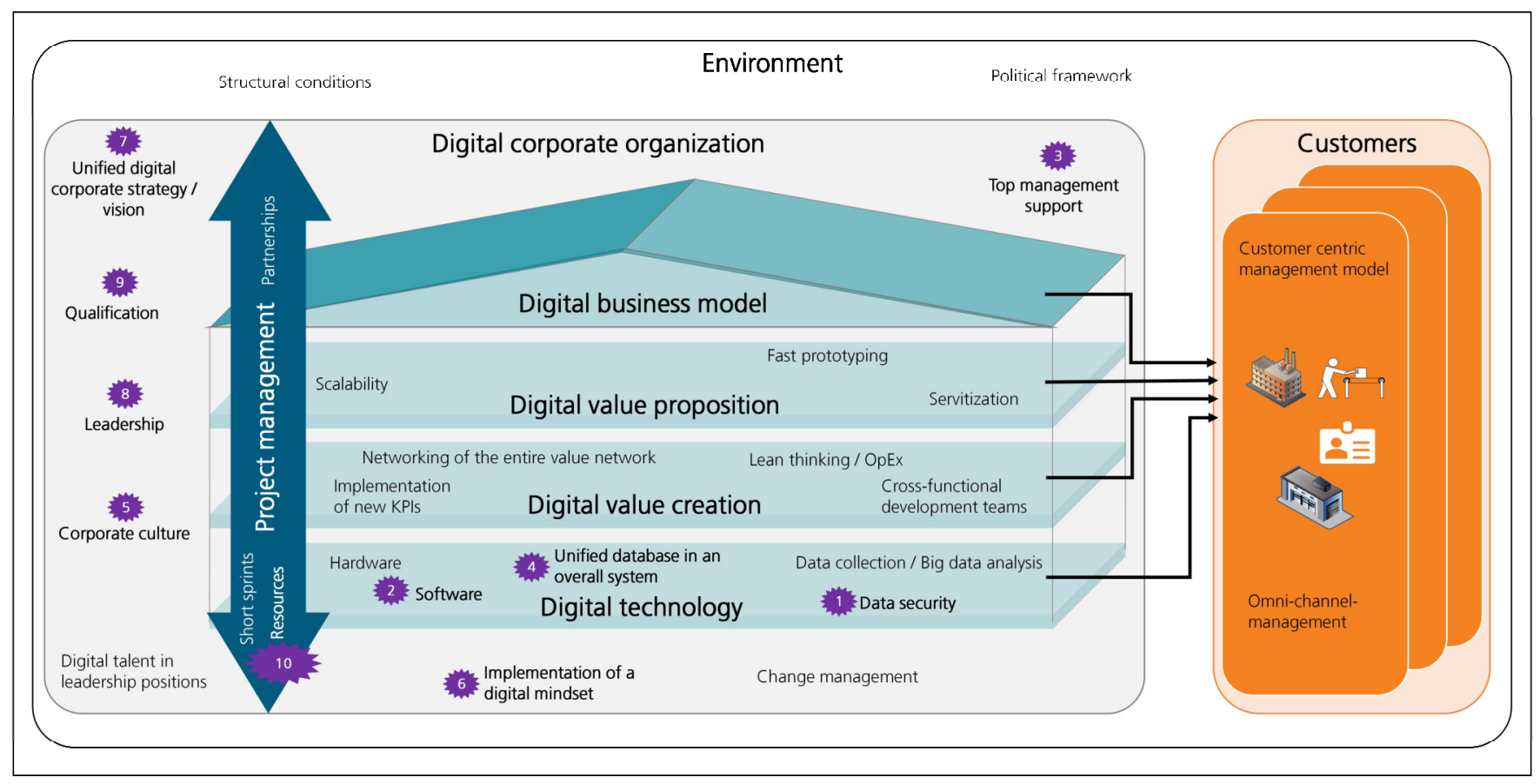

Fig. 1. Model of Digital Transformation - Integration of Dimensions and Critical Success Factors

\section{CONCLUSION}

The results of our study make a significant contribution to the CSF research focusing on digitalization projects. Future research activities in this topic area can build on the insights gained from our study. For example, individual factors, such as the Top 3 CSFs Corporate culture, Unified digital corporate strategy / vision, and Top management support, could be investigated in more detail to derive recommendations for action for the best possible implementation of the CSFs in the company. Furthermore, qualitative and quantitative studies (with claim to 
representativity) can be conducted in individual industry sectors and with a more specific consideration of company sizes to further specify the importance of CSFs for digitalization projects in this regard. Another starting point for future research could be to analyze CSFs with reference to the different types of digitalization projects, such as logistics or human resources, to highlight any differences. Furthermore, it should be investigated what makes the implementation of individual CSFs in companies more difficult and how these obstacles can be minimized.

The need for a more detailed and diversified view of different CSFs becomes even more evident when considering the potential impact of the COVID-19 crisis on DT. The crisis brought DT into sharper focus, especially for companies that had not previously addressed DT in such detail. This is also illustrated by the answers to the question focusing on the influence of the COVID-19 crisis. Even though nearly $60 \%$ of the companies had seen DT as important before the pandemic, an additional 33\% now see DT as more important than before. In conclusion, this shows the importance of focusing strongly on DT in research and deriving concrete practice-oriented recommendations for action and assistance for companies in shaping DT. By discussing CSFs within the context of the COVID-19 crisis, different questions on shortterm and long-term time horizons are implied, e.g., what changes were organizations able to implement ad hoc, what are the lessons learned, which changes will remain after the COVID-19 crisis? At the interface of digitalization projects, the call for new work imperatives came up. However, since the advancement/adaption strategies of large companies are often clearer than the respective coping mechanisms of SMEs, we are currently working on a study that focuses on CSFs for improved data management and data analysis within SMEs (as an exemplary digitalization project) in times of the COVID-19 crisis.

\section{REFERENCES}

[1] R. G. Fichman, B. L. Dos Santos, and Z. (Eric) Zheng, "Digital Innovation as a Fundamental and Powerful Concept in the Information Systems Curriculum," MIS Quarterly, vol. 38, no. 2, pp. 329-343, 2014, doi: 10.25300/MISQ/2014/38.2.01.

[2] C. Leyh, T. Schäffer, K. Bley, and S. Forstenhäusler, "Assessing the IT and Software Landscapes of Industry 4.0-Enterprises: The Maturity Model SIMMI 4.0," in Information Technology for Management: New Ideas and Real Solutions, Lecture Notes in Business Information Processing, LNBIP, Vol. 277, E. Ziemba, Ed. Cham: Springer, 2017, pp. 103-119. doi: 10.1007/978-3-319-53076-5_6.

[3] M. Pagani, "Digital Business Strategy and Value Creation: Framing the Dynamic Cycle of Control Points," MIS Quarterly, vol. 37, no. 2, pp. 617-632, 2013, doi: 10.25300/MISQ/2013/37.2.13.

[4] C. Leyh, K. Bley, and M. Ott, "Chancen und Risiken der Digitalisierung - Befragungen ausgewählter KMU," in Arbeit 4.0 - Digitalisierung, IT und Arbeit, J. Hofmann, Ed. Wiesbaden: Springer, 2018, pp. 29-51. doi: 10.1007/978-3-658-21359-6_3.

[5] S. Mathrani, A. Mathrani, and D. Viehland, "Using enterprise systems to realize digital business strategies," Journal of Enterprise Information Management, vol. 26, no. 4, pp. 363-386, 2013, doi: 10.1108/JEIM-012012-0003.

[6] K. Bley, C. Leyh, and T. Schäffer, "Digitization of German Enterprises in the Production Sector - Do they know how 'digitized' they are?," in Proceedings of the 22nd Americas Conference on Information Systems (AMCIS 2016), 2016.
[7] C. Helmenstein, M. Zalesak, J. El-Rayes, and P. Krabb, "Raise the Curve: Mit Digitalisierung zu mehr Resilienz und Wachstum," Accenture and Industriellenvereinigung, 2020.

[8] A. Berg, "Digitalisierung der Wirtschaft - Auswirkungen der CoronaPandemie," Berlin: bitkom, 2020.

[9] K.-H. Streibich and J. Winter, "Resiliente Vorreiter aus Wirtschaft und Gesellschaft," Munich: acatech — Deutsche Akademie der Technikwissenschaften, 2020.

[10] Deutsche Telekom AG, "Der digitale Status quo des deutschen Mittelstands - Digitalisierungsindex Mittelstand 2020/2021," techconsult $\mathrm{GmbH}$ and Deutsche Telekom AG, 2020.

[11] A. Jones, J. Robinson, B. O'Toole, and D. Webb, "Implementing a bespoke supply chain management system to deliver tangible benefits," The International Journal of Advanced Manufacturing Technology, vol. 30, no. 9-10, pp. 927-937, 2006, doi: 10.1007/s00170-005-00652 .

[12] R. Hentschel, C. Leyh, and T. Baumhauer, "Critical Success Factors for the Implementation and Adoption of Cloud Services in SMEs," in Proceedings of the 52nd Hawaii International Conference on System Sciences (HICSS 2019), 2019.

[13] P. Achanga, E. Shehab, R. Roy, and G. Nelder, "Critical success factors for lean implementation within SMEs," Journal of Manufacturing Technology Management, vol. 17, no. 4, pp. 460-471, 2006, doi: $10.1108 / 17410380610662889$.

[14] C. Leyh and J. Thomschke, "Critical Success Factors for Implementing Supply Chain Management Systems - The Perspective of Selected German Enterprises," in Proceedings of the 2015 Federated Conference on Computer Science and Information Systems (FedCSIS 2015), 2015, pp. 1403-1413. doi: 10.15439/2015F245.

[15] J. M. Denolf, J. H. Trienekens, P. M. (Nel) Wognum, J. G. A. J. van der Vorst, and S. W. F. (Onno) Omta, "Towards a framework of critical success factors for implementing supply chain information systems," Computers in Industry, vol. 68, pp. 16-26, 2015, doi: 10.1016/j.compind.2014.12.012.

[16] F. Holotiuk and D. Beimborn, "Critical Success Factors of Digital Business Strategy," in Proceedings der 13. Internationalen Tagung Wirtschaftsinformatik (WI 2017), 2017.

[17] C. Leyh and L. Crenze, "ERP System Implementations vs. IT Projects: Comparison of Critical Success Factors," in Enterprise Information Systems of the Future, Lecture Notes in Business Information Processing, LNBIP, Vol. 139, G. Poels, Ed. Berlin, Heidelberg: Springer, 2013, pp. 223-233. doi: 10.1007/978-3-642-36611-6_20.

[18] C. Leyh and N. Meischner, "Erfolgsfaktoren von Digitalisierungsprojekten - Einflussfaktoren auf Projekte zur Digitalen Transformation von Unternehmen," ERP Management, vol. 2/2018, pp. 35-38, 2018, doi: 10.30844/ERP18-2_35-38.

[19] R. Sauer, M. Dopfer, J. Schmeiss, and O. Gassmann, "Geschäftsmodell als Gral der Digitalisierung," in Digitale Transformation im Unternehmen gestalten: Geschäftsmodelle, Erfolgsfaktoren, Handlungsanweisungen, Fallstudien, O. Gassmann and P. Sutter, Eds. Munich: Hanser, 2016, pp. 15-27.

[20] E. Wallmüller, Praxiswissen Digitale Transformation: Den Wandel verstehen, Lösungen entwickeln, Wertschöpfung steigern. Munich: Hanser, 2017. doi: 10.3139/9783446452732.

[21] D. Barghop, E. Deekeling, and D. Schweer, "Herausforderung Disruption: Konsequenzen und Erfolgsfaktoren für die Kommunikation," in Kommunikation in der digitalen Transformation, E. Deekeling and D. Barghop, Eds. Wiesbaden: Springer, 2017, pp. 519. doi: 10.1007/978-3-658-17630-3_2.

[22] C. Falkenreck, Digitalisierungsprojekte erfolgreich planen und steuern: Kunden und Mitarbeiter für die digitale Transformation begeistern. Wiesbaden: Springer, 2019. doi: 10.1007/978-3-65824890-1.

[23] A. Nicolai and A. Kieser, "Trotz eklatanter Erfolgslosigkeit: Die Erfolgsfaktorenforschung weiter auf Erfolgskurs," Die Betriebswirtschaft, vol. 62, no. 6, pp. 579-596, 2002.

[24] D. R. Daniel, "Management Information Crisis," Harvard Business Review, vol. 39, no. 5, pp. 111-121, 1961.

[25] J. F. Rockart, "Chief executives define their own data needs," Harvard Business Review, vol. 57, no. 2, pp. 81-93, 1979.

[26] C. W. Hofer and D. Schendel, Strategy formulation: analytical concepts. St. Paul/Minnesota: West Publishing, 1978. 
[27] J. K. Leidecker and A. V. Bruno, "Identifying and using critical success factors," Long Range Planning, vol. 17, no. 1, pp. 23-32, 1984, doi: 10.1016/0024-6301(84)90163-8.

[28] G. Wokurka, Y. Banschbach, D. Houlder, and R. Jolly, "Digital Culture: Why Strategy and Culture Should Eat Breakfast Together," in Shaping the Digital Enterprise, G. Oswald and M. Kleinemeier, Eds. Cham: Springer, 2017, pp. 109-120. doi: 10.1007/978-3-319-4096725 .

[29] J. vom Brocke, M. Fay, T. Schmiedel, M. Petry, F. Krause, and T. Teinzer, "A Journey of Digital Innovation and Transformation: The Case of Hilti," in Shaping the Digital Enterprise, G. Oswald and M. Kleinemeier, Eds. Cham: Springer, 2017，pp. 237-251. doi: 10.1007/978-3-319-40967-2 12 .
[30] B. J. Weiner, "A theory of organizational readiness for change," Implementation Science, vol. 4, no. 67, 2009, doi: 10.1186/1748-9084-67.

[31] Q. Hu, T. Dinev, P. Hart, and D. Cooke, "Managing Employee Compliance with Information Security Policies: The Critical Role of Top Management and Organizational Culture," Decision Sciences, vol. 43, no. 4, pp. 615-660, 2012, doi: 10.1111/j.15405915.2012.00361.x.

[32] S. Ries, "Veränderungen in kleinen und mittelständischen Unternehmen: Innerbetrieblichen Widerstand überwinden, Unterstützung von Veränderung herbeiführen und organisationale Veränderungsbereitschaft leben," Leipzig: Fraunhofer Center for International Management and Knowledge Economy IMW, 2021. 